\title{
Characterization and Thermal Stability Properties of Bulk Hierarchical Porous Pd Prepared by Kirkendall Effect and Dealloying Method
}

\author{
Wei Feng, ${ }^{1,2}$ Qingquan Kong $\mathbb{D},{ }^{1,2}$ Xiaodong Zhu, ${ }^{1}$ Xinxin Xie, ${ }^{1}$ Huajiang Zhou, \\ Youxu Qiu, ${ }^{3}$ and Chenghua Sun (i) ${ }^{4}$ \\ ${ }^{1}$ School of Mechanical Engineering, Chengdu University, Chengdu 610106, China \\ ${ }^{2}$ College of Architecture and Environment, Sichuan University, Chengdu 610065, China \\ ${ }^{3}$ Investment Promotion Agency, State High- and New-Tech Industrial Development Zone of Zigong, Zigong 643000, China \\ ${ }^{4}$ Department of Chemistry and Biotechnology, Faculty of Science, Engineering and Technology, Swinburne University of Technology, \\ Hawthorn, VIC 3122, Australia
}

Correspondence should be addressed to Qingquan Kong; kongqingquan@163.com and Chenghua Sun; chenghua.sun@monash.edu

Received 22 September 2017; Revised 17 December 2017; Accepted 3 January 2018; Published 5 April 2018

Academic Editor: Mohamed Bououdina

Copyright (C) 2018 Wei Feng et al. This is an open access article distributed under the Creative Commons Attribution License, which permits unrestricted use, distribution, and reproduction in any medium, provided the original work is properly cited.

\begin{abstract}
We present a facile strategy to synthesize bulk hierarchical porous Pd materials (BHPPd) with pores ranging from a few nanometers to tens of micrometers through chemical dealloying of porous PdAl intermetallics. Owing to the small surface diffusivities of Pd atoms, the pore/ligament size of BHPPd did not coarsen remarkably as the concentration of $\mathrm{HCl}$ aqueous solution increases. Thermal stability properties of BHPPd materials at different temperature ranging from 673 to $1073 \mathrm{~K}$ were evaluated. BHPPd materials show superior thermal stability, whose bicontinuous interpenetrating ligament-channel structure can be maintained even after being annealed at $1073 \mathrm{~K}$ for $30 \mathrm{~min}$. Such properties can be attributed to less defects and less-noble metal residues. Moreover, compression properties of BHPPd materials were also investigated.
\end{abstract}

\section{Introduction}

Nanostructured Pd has been used as active materials in many fields such as hydrogen isotopes separation [1], hydrogen storage and purification [2], catalysis [3], sensing [4, 5], and electrochemical actuation [6,7]. Recently, dealloying method was developed as a simple and effective way to fabricate nanoporous metals, which refers to the selective dissolution of less-noble components out of a precursor alloy and combined with aggregation of more-noble elements via surface diffusion $[8,9]$. For instance, nanoporous Pd with fine pore/ligaments can be fabricated by the aforesaid dealloying method $[10,11]$. However, early investigations of nanoporous Pd mainly focused on the synthesis of porous metals films or powder with homogeneous pore size distributions, whereas bulk Pd-structure with hierarchical pours is poorly studied. Bimodal porous metal materials have many industry applications $[6,12]$, for which pores often play key roles; thus it is of great technical significance to understand the stability of bulk porous bimetals.

In the literature, Qi and Weissmüller reported the synthesis of bulk metals with a hierarchical microstructure by electrochemical dealloying and annealing strategy [13]. Du et al. provided a convenient method to prepare micro/nanoporous metal materials by Gasar process and then chemical dealloying [14]. Cox and Dunand introduced a facile technique to fabricate hierarchical porous bulk gold materials with macro-, micro-, and nanoporosity, which were, respectively, formed by salt replication, gas expansion, and dealloying method [15]. However, these techniques are complicated and make it difficult to obtain open pores and/or free-standing bulk nanoporous materials. A novel method was reported for the fabrication of porous TiAl alloys by the Kirkendall effect, with pore size distribution controlled readily from micrometers to nanometers [16]. Thus, hierarchical porous bimetals can be obtained through chemical 


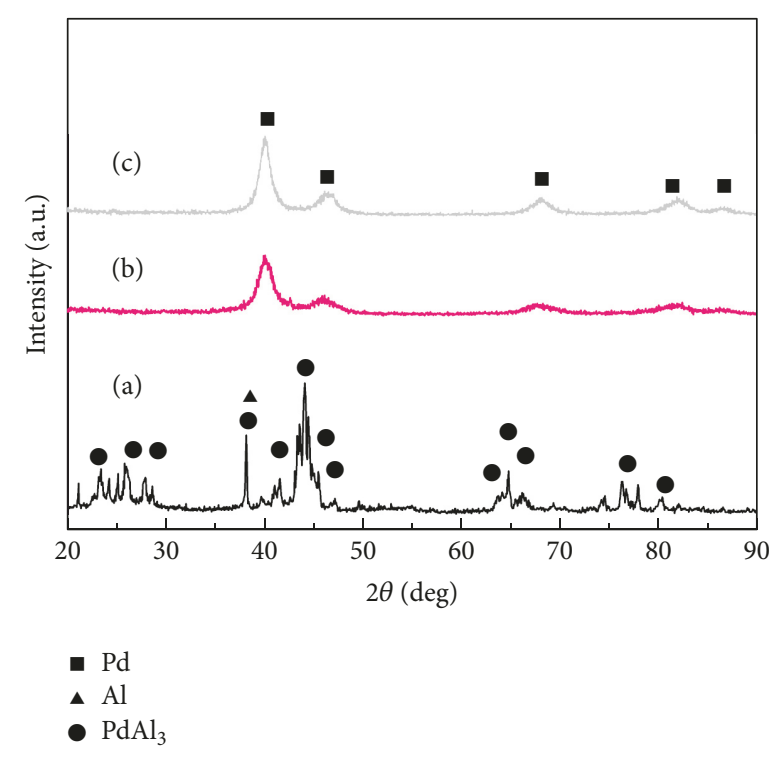

FIGURE 1: XRD patterns of (a) porous PdAl intermetallic and their as-dealloyed sample after being eroded in different concentration of $\mathrm{HCl}$ solutions. (b) $0.1 \mathrm{M} \mathrm{HCl}, 10 \mathrm{~d}$; (c) $0.5 \mathrm{M} \mathrm{HCl}, 10 \mathrm{~d}$.

dealloying of porous intermetallics fabricated through Kirkendall effect.

Here, we demonstrated that such a two-step strategy, Kirkendall fabrication followed by chemical dealloying, can be employed to fabricate bulk Pd-structures with hierarchical pores, namely, BHPPd. Thermal stability of BHPPd was further investigated by heat treatment in flowing Ar environment at various temperature. In addition, compressive properties of BHPPd were also investigated.

\section{Experimental}

Al powder $(>99.9 \%, \sim 2 \mu \mathrm{m}$, ST NANO, China) and spongy Pd (>99.95\%, $\sim 30 \mu \mathrm{m}$, Northwest Institute for Nonferrous Metal Research, China) were utilized as raw materials in this work. $\mathrm{Pd}$ and $\mathrm{Al}$ powders with the atom ratio of $\mathrm{Pd}: \mathrm{Al}=2: 8$ were blended in acetone and then dried at room temperature. The compact discs were prepared by cold pressing with $P$ $=200 \mathrm{MPa}$ for $15 \mathrm{~s}$. Subsequently, the green compacts were sintered in a silica tubular furnace with a temperature of $873 \mathrm{~K}$ for $4 \mathrm{~h}$ under Ar atmosphere. The heating rate was set to $2 \mathrm{~K} / \mathrm{min}$ in order to maintain the original shape of the compact discs, with porous PdAl intermetallics prepared. Porous PdAl intermetallics were then immersed in $\mathrm{HCl}$ aqueous solution at room temperature to fabricate BHPPd materials. The as-dealloyed samples were rinsed with distilled water and dehydrated alcohol. To investigate the effect of temperature on the microstructure of BHPPd materials, the as-dealloyed samples were annealed at $673 \mathrm{~K}, 873 \mathrm{~K}$, and $1073 \mathrm{~K}$ in the flowing Ar environment, respectively.

Field-emission scanning electron microscope (Hitachi S4800) and transmission electron microscope (FEI Tecnai G2 F20 S-TWIN) were utilized to characterize the microstructure of prepared materials. X-ray diffractometer (XRD, DX2000) with $\mathrm{Cu} \mathrm{K} \alpha$ radiation was utilized to record the
X-ray diffraction patterns (XRD) of samples. Surface areas of the resultant BHPPd materials were measured by a $\mathrm{N}_{2}$ adsorption apparatus. Average ligament diameters were then measured from the FE-SEM images of more than 100 ligaments by Image J software. Furthermore, differential scanning calorimetry (DSC, Mettler Toledo) was performed on the as-dealloyed BHPPd materials under constant Ar flow with a standard Pt pan container. The sample mass was $6.668 \mathrm{mg}$. The heating rate was $20 \mathrm{~K} / \mathrm{min}$ and the maximum temperature was $1300 \mathrm{~K}$. The compressive strength tests were carried out through an Instron mechanical testing machine (Instron 4302) with a crosshead speed of $0.5 \mathrm{~mm} / \mathrm{min}$. At least three specimens were tested for each sample.

\section{Results and Discussion}

3.1. Characterization of BHPPd Materials. Figure 1 shows XRD patterns of porous $\mathrm{PdAl}$ intermetallic and their asdealloyed samples. As shown in Figure 1(a), the porous PdAl intermetallic exhibits typically diffraction peaks of $\mathrm{PdAl}_{3}$ and $\mathrm{Al}$, confirming that the prepared $\mathrm{PdAl}$ intermetallics consist of $\mathrm{PdAl}_{3}$ and $\mathrm{Al}$ phase. From Figures 1(b) and 1(c), only $\mathrm{Pd}$ phase can be detected, suggesting that $\mathrm{PdAl}_{3}$ phase can be fully dealloyed in $\mathrm{HCl}$ solution.

Figure 2 shows microstructure of porous $\mathrm{PdAl}$ compacts before and after sintering. As shown in Figure 2(a), it can be observed that Pd particles were dispersed distribution in the Al matrix after the mixing. From Figure 2(b), porous structures were formed after sintering due to the Kirkendall effect, being similar with the fabrication of porous TiAl [16]. Figure 2(c) shows the optical image of porous PdAl compacts before (A) and after (B) sintering. The original shape of green compact can be maintained after sintering. Additionally, the color of the green compact becomes white gray. On the contrary, the color of porous PdAl compact after sintering is dark gray, indicating that new phases were formed. Combining XRD analysis and microstructure observations, we can conclude that porous PdAl intermetallics were successfully prepared.

FE-SEM images of the as-dealloyed porous PdAl intermetallics are shown in Figure 3; bulk hierarchical porous Pd materials (BHPPd) with both larger pores of tens micrometers (Figures 3(a) and 3(c)) and smaller pores of a few nanometers (Figures 3(b) and 3(d)) can be observed. The larger pores come from original pores of PdAl intermetallic structures, which can be tailored by changing the content and particle size of $\mathrm{Al}[16,20]$. The smaller pores were obtained by dealloying of $\mathrm{PdAl}_{3}$ phase. Specifically, dealloying mechanism of PdAl alloy is that less-noble $\mathrm{Al}$ can be selectively dissolved, and then more-noble Pd atoms were aggregated to form nanoporous Pd [21]. The prepared porous PdAl intermetallics are mainly composed of $\mathrm{PdAl}_{3}$ compound, which can be eroded in $\mathrm{HCl}$ solution. Afterward, the remaining Pd atoms were rearranged to form nanoporous structure. EDS pattern shown in the inset image in Figure 3(d) shows that only Pd element can be detected in the resultant samples. With the combination of XRD results mentioned above, it was confirmed that BHPPd materials with high purity were fabricated. Moreover, it is interesting to note that the 


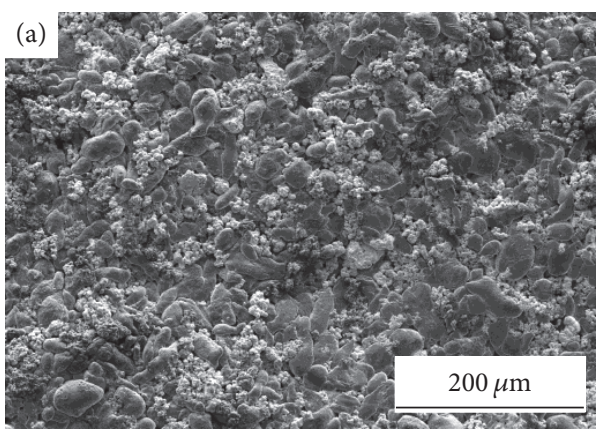

(a)

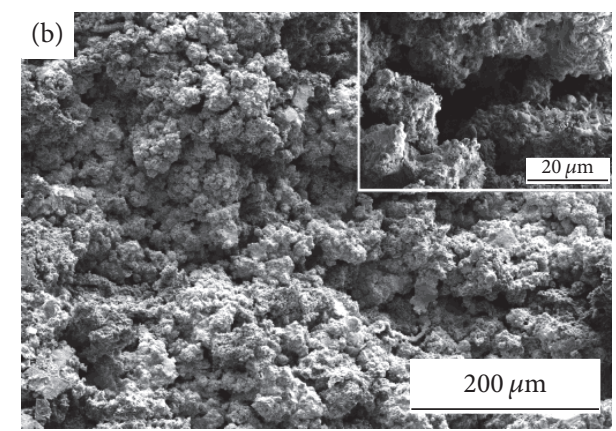

(b)

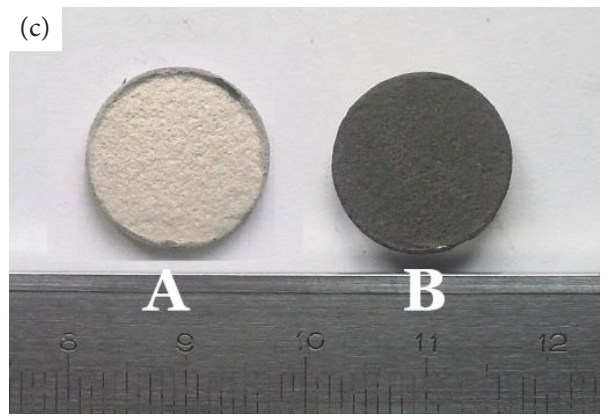

(c)

FIgUre 2: Microstructure of porous PdAl compacts. (a) FE-SEM images of green compact, (b) sintered at $873 \mathrm{~K}$ and $4 \mathrm{~h}$, and (c) optical photograph of porous PdAl compacts before (A) and after (B) sintering.

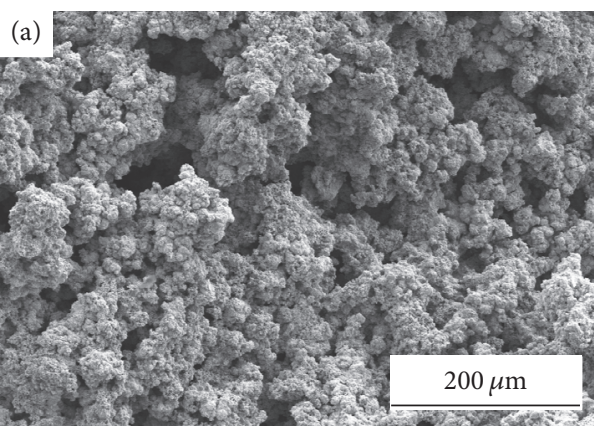

(a)

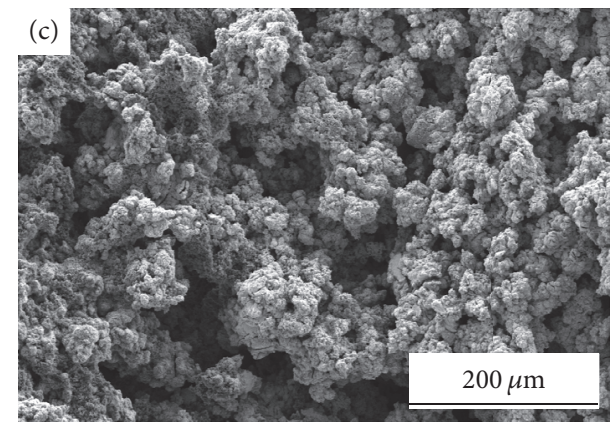

(c)

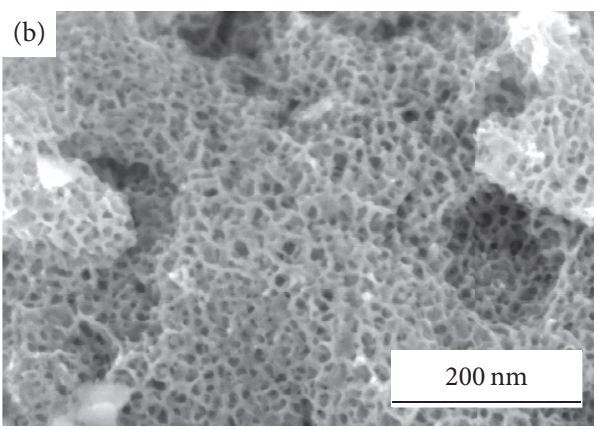

(b)

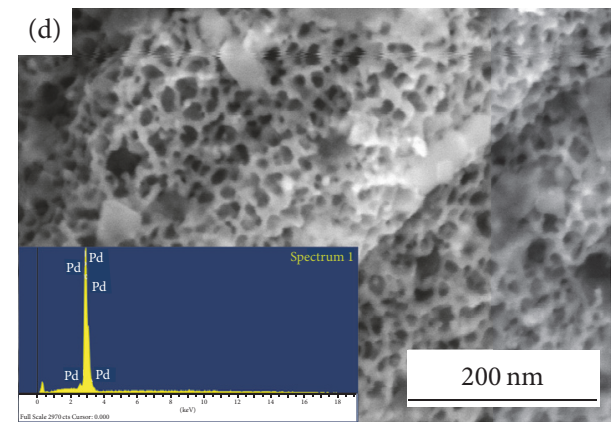

(d)

FIGURE 3: FE-SEM images of BHPPd after being dealloyed in different concentration of $\mathrm{HCl}$ solutions. (a, b) $0.1 \mathrm{M} \mathrm{HCl}, 10 \mathrm{~d}$; (c, d) $0.5 \mathrm{M} \mathrm{HCl}$, $10 \mathrm{~d}$. 


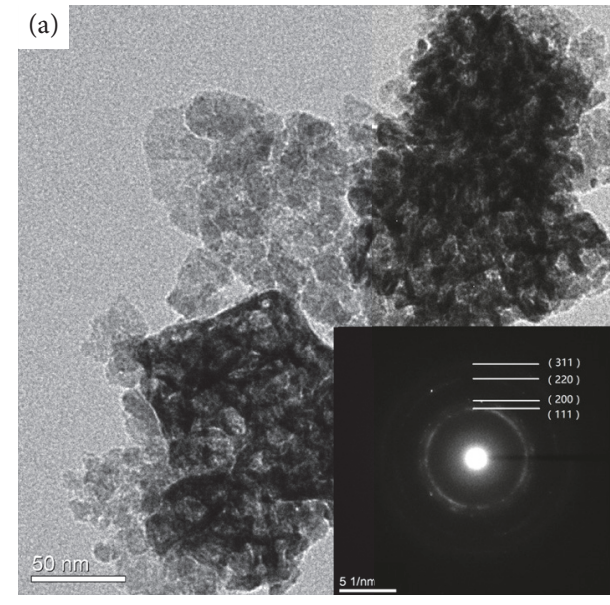

(a)

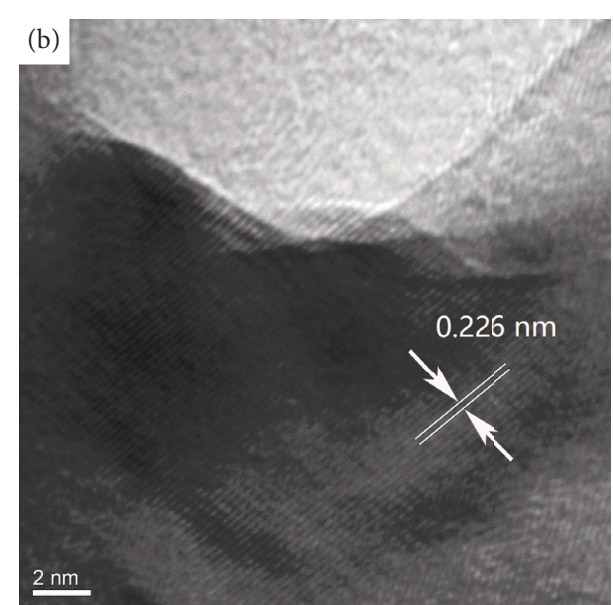

(b)

FIGURE 4: TEM images of BHPPd after being dealloyed in $0.1 \mathrm{M} \mathrm{HCl}$ solutions.

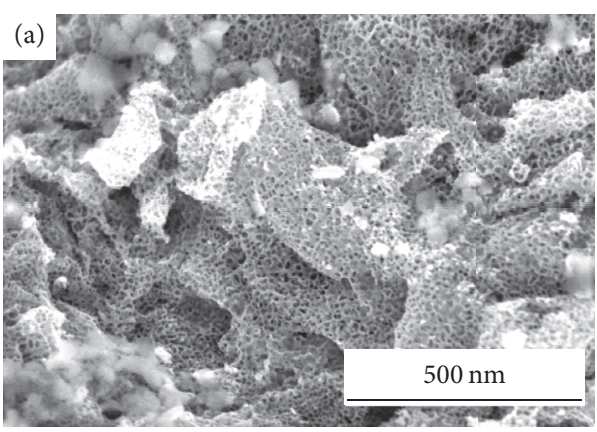

(a)

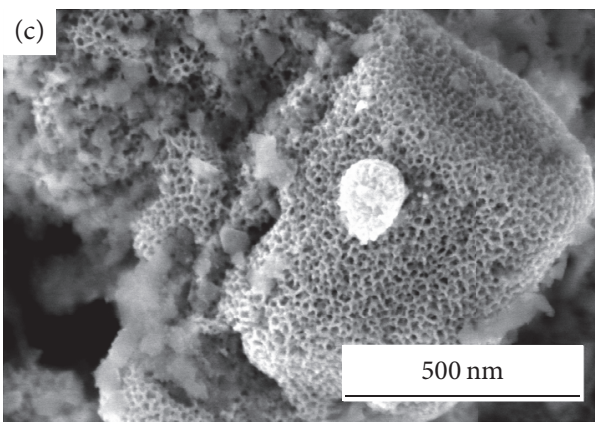

(c)

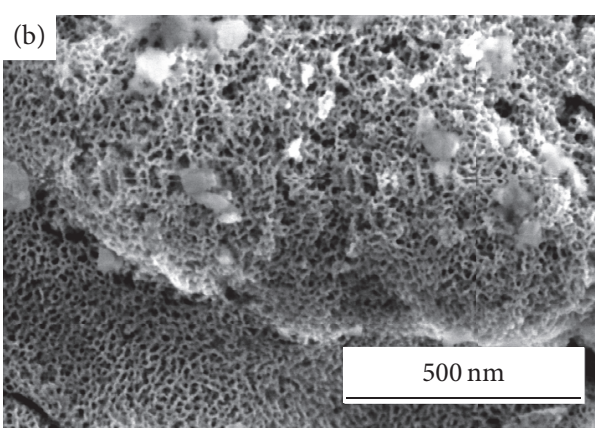

(b)

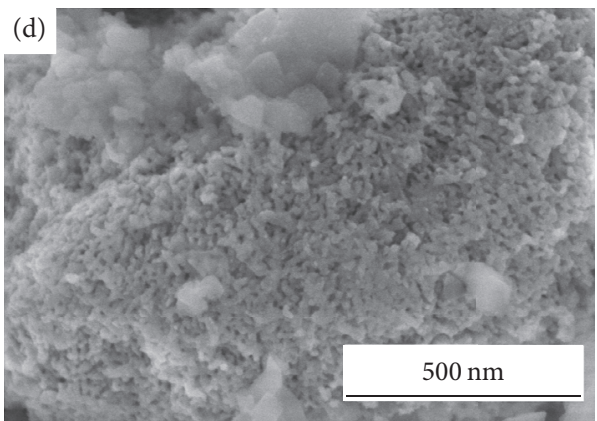

(d)

FigURE 5: FE-SEM images of BHPPd after being annealed at various temperature. (a) As-dealloyed, (b) $673 \mathrm{~K}$, (c) $873 \mathrm{~K}$, and (d) $1073 \mathrm{~K}$.

pore/ligament size of BHPPd did not coarsen obviously and even the concentration of $\mathrm{HCl}$ aqueous solution increased from $0.1 \mathrm{M}$ to $0.5 \mathrm{M}$ (Figures $3(\mathrm{~b})$ and $3(\mathrm{c})$ ), which can be attributed to the small surface diffusivities of Pd atoms [21].

Figure 4 shows TEM images of BHPPd after being dealloyed in $0.1 \mathrm{M} \mathrm{HCl}$ solutions. As shown in Figure 4(a), bicontinuous interpenetrating ligament-channel structure of BHPPd materials can be further confirmed. The inset images in Figure 4(a) are selected area electron diffraction (SAED) of BHPPd, indicating that the ligament is composed of nanocrystalline Pd instead of single crystal. The lattice spacing was approximately $0.226 \mathrm{~nm}$, based on the measurement from the HR-TEM shown in Figure 4(b), which is equal to (110) plane of Pd.

3.2. Thermal Stability Properties. Figure 5 shows FE-SEM images of BHPPd materials after being annealed at various temperature for $30 \mathrm{~min}$. From the images, bicontinuous interpenetrating ligament-channel structure of BHPPd materials can be observed. Moreover, it is worth noting 


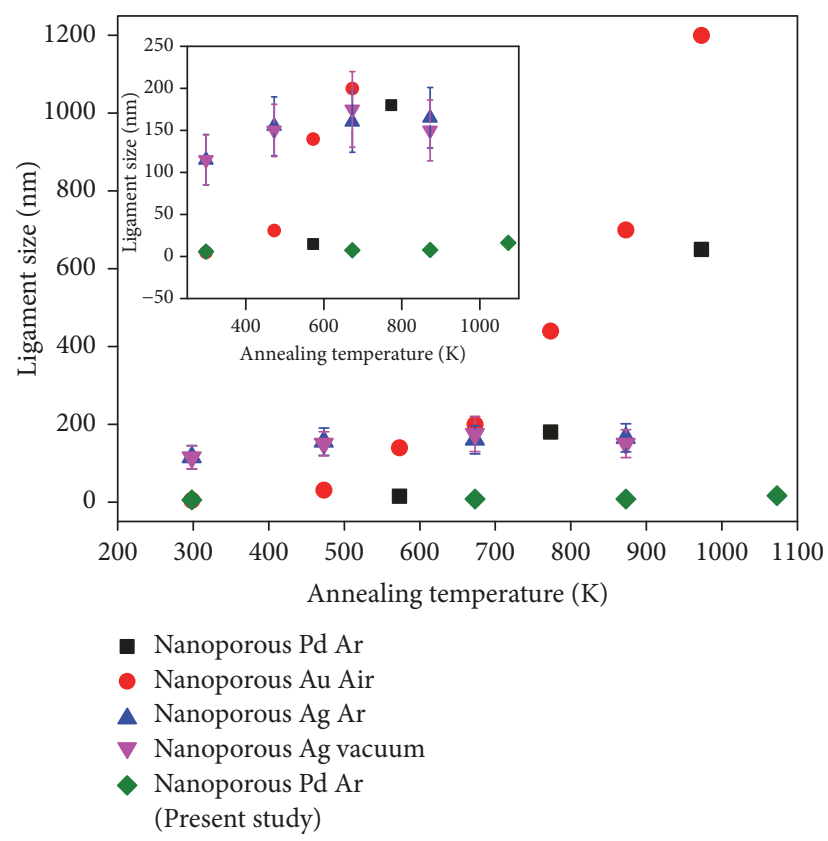

FIGURE 6: Relationship between annealing temperature and ligament size of annealed BHPPd materials. Results of nanoporous Pd (annealed at Ar atmosphere) [17], nanoporous Au (annealed at air atmosphere) [18], and nanoporous Ag (annealed at Ar atmosphere and vacuum) [19] were also shown for comparison.

that ligament/pore of BHPPd slightly coarsens even after being annealed at $1073 \mathrm{~K}$ for $30 \mathrm{~min}$, suggesting high stability property. Hakamada and Mabuchi reported that both pore size and ligament size of nanoporous $\mathrm{Pd}$, prepared by electrochemical dealloying PdCo alloy, were significantly increased after annealing treatment. The average ligament size of nanoporous $\mathrm{Pd}$ after being annealed at $773 \mathrm{~K}$ is $180 \mathrm{~nm}$ [17]. These phenomena were often called thermal coarsening, as observed in nanoporous materials such as $\mathrm{Au}$ [22]. Tuning the ligament size and pore size distribution of porous materials by thermal coarsening can lead to the optimization of their application performance [23-25]. However, for the application in high temperature environment, thermal coarsening may cause the degradation of properties [26, 27].

Relationship between annealing temperature and ligament size of annealed BHPPd materials is shown in Figure 6. Results of other reports were also shown for comparison [17-19]. Nanoporous Pd (annealed at Ar atmosphere) [17] and nanoporous $\mathrm{Au}$ (annealed at air atmosphere) [18] were unstable at high temperature, whose ligaments coarsen remarkably as increment of annealing temperature. As a contrast, nanoporous Ag (annealed at Ar atmosphere and vacuum, resp.) [19] and present BHNPPd materials show excellent thermal stability.

According to the previous reports, thermal stability properties of nanoporous metal can be affected by the following factors such as gas species and original pore structure [2731]. For instance, Kuwano-Nakatani et al. reported that nanoporous $\mathrm{Au}$ were significantly coarsening in both air and chemically active diatomic gas $\left(\mathrm{N}_{2}\right.$ and $\left.\mathrm{O}_{2}\right)$, but not in vacuum and inert monoatomic gas (Ar) [30]. Our annealing

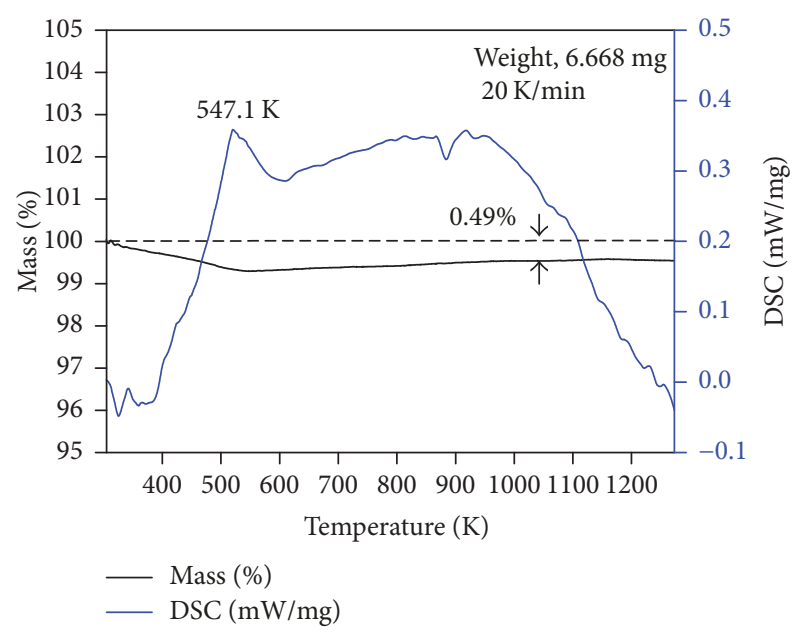

FiguRE 7: DSC results for BHPPd.

treatment was carried out under Ar atmosphere, similar with Hakamada and Mabuchi's study [17], but different thermal coarsening performance was found, so the thermal stability of BHPPd in the present study may attribute to other factors, as discussed below.

Pore diameter is also identified as an important factor to determine the thermal stability of nanoporous noble metals [28]. For instance, nanoporous Pd with larger and more regular mesopores are stable than that with pore size below a critical diameter of 4-7 $\mathrm{nm}$ range at high temperatures [28]. Figure 7 shows the DSC result for the BHPPd materials, a broad exothermal peak was detected at approximately $550 \mathrm{~K}$. The exothermal peak represents recovery-like process or recrystallization during annealing process [18]. In our study, the start pore/ligament size of BHPPd is smaller than that of Masataka's study, and it also has a high BET area of $\sim 55 \mathrm{~m}^{2} / \mathrm{g}$ according to Nitrogen adsorption test. Such extraordinarily large surface area and fine pore of the BHPPd seem to be beneficial for the thermal coarsening.

Electrochemical dealloying of PdCo alloy was utilized to prepare nanoporous Pd in Hakamada and Mabuchi's study, which may result in the formation of large amount of microstructure defects with respect to corrosion-free case [17]. As microstructure defects can promote the thermal coarsening, we did not observe large amount of microstructure defects in the BHPPd materials prepared in this study (as shown in Figure 4(b)), which should be one reason for the observed superior thermal stability.

Earlier, nanoporous Au has been synthesized through the dealloying of solid solution Au-Ag alloy through a phase separation process (also called spinodal decomposition) at the solid-electrolyte interface $[8,32]$. The concentration of more-noble component should be below the parting limit [33]. As a result, less-noble components such as Ag and Co can be retained in the resultant nanoporous metal after being dealloyed [2,34]. The Ag residue is preferred for the ligament coarsening of nanoporous $\mathrm{Au}$ in annealing process by modifying the surface diffusivity of $\mathrm{Au}$ atoms [35, 36]. Ligament sizes of nanoporous $\mathrm{Au}$ increase from 160 to $246 \mathrm{~nm}$ after heat treatment at $573 \mathrm{~K}$, depending on the resident $\mathrm{Ag}$ 


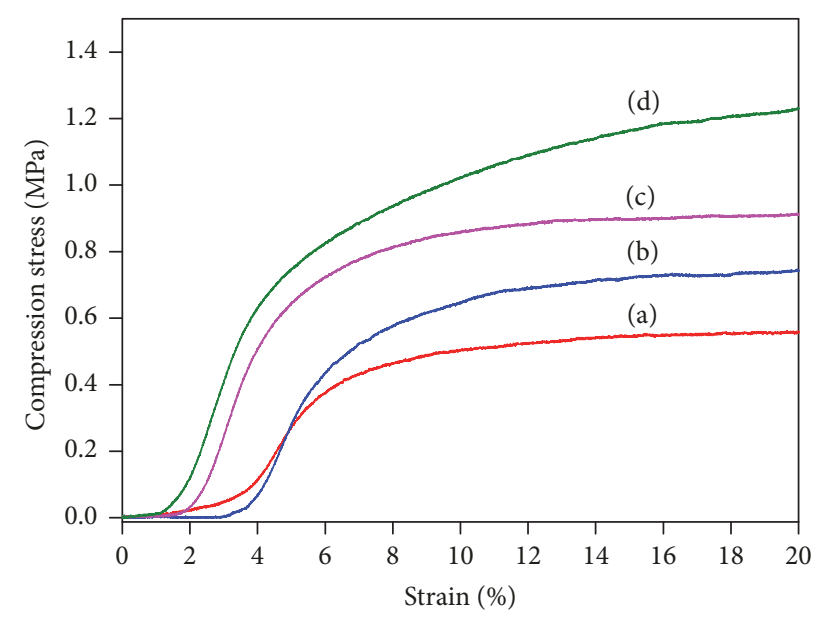

FIGURE 8: Strain-stress curve of BHPPd. (a) As-dealloyed, annealed at (b) $673 \mathrm{~K}$, (c) $873 \mathrm{~K}$, and (d) $1073 \mathrm{~K}$.

content [35]. Co impurities also can be propitious for the thermal coarsening of nanoporous Pd [2]. For intermetallics, less-noble element rich phase can be fully dealloyed [37]. In this study, the porous Pd intermetallics consist of $\mathrm{PdAl}_{3}$ and $\mathrm{Al}$ phases, as clarified by XRD, which can be fully dealloyed in $\mathrm{HCl}$ solution. Thus, the absence of less-noble elements (Al in this case) after dealloying may affect the thermal stability properties of nanoporous $\mathrm{Pd}$, which will be further investigated in the future study.

3.3. Compression Properties. Mechanical properties for porous Pd materials are very important for their engineering application where service gas or liquid flow is concerned [38]. Compression stress-strain curves of BHPPd materials are shown in Figure 8. The as-dealloyed BHPPd has a very low yield strength of $0.56 \mathrm{MPa}$. The annealed BHPPd samples have an improved yield strength of $1.23 \mathrm{MPa}$ after being annealed at $1073 \mathrm{~K}$. Annealing method was developed as a facile technique to enhance the mechanical properties of nanoporous materials $[13,15]$. Bulk porous Au with hierarchical porosity annealed at $873 \mathrm{~K}$ shows good compressive strength than the as-dealloyed one [15]. After being annealed at a relative high temperature, however, ligament diameter is remarkably increased, leading to a reduction in surface area and surface curvature [15]. The present BHPPd materials show preferable good thermal stability, which opens the door to obtain strong BHPPd without dramatically degradation of the porous structure.

\section{Conclusion}

In summary, BHPPd materials have been fabricated by Kirkendall effect combined with dealloying method. Due to the small surface diffusion rate of Pd, the pore/ligament size of BHPPd did not coarsen remarkably as the concentration of $\mathrm{HCl}$ aqueous solution increased. BHPPd materials also show excellent thermal stability, which can be potentially utilized in related high temperature environment. The main causes for good thermal stability of BHPPd can be attributed to less microstructure defects and little less-noble element residue. Moreover, annealing treatment can improve the compression strength of BHPPd, with a compressive strength of $\sim 1.23 \mathrm{MPa}$ achieved after annealing at $1073 \mathrm{~K}$.

\section{Conflicts of Interest}

The authors declare that there are no conflicts of interest regarding the publication of this paper.

\section{Acknowledgments}

The authors would like to acknowledge funding from the School Foundation of Chengdu University (2080516030), the Open Foundation of Key Laboratory of Special Materials and Manufacturing Technology in Sichuan Provincial Universities (szjj2017-062), Sichuan Engineering Research Center for Powder Metallurgy (SC-FMYJ2017-05), the Training Program for Innovation of Chengdu University (CDU-CX2017016), and the National Natural Science Foundation of China (11572057).

\section{References}

[1] S. Fukada and H. Fujiwara, "Comparison of chromatographic methods for hydrogen isotope separation by Pd beds," Journal of Chromatography A, vol. 898, no. 1, pp. 125-131, 2000.

[2] M. Hakamada, H. Nakano, T. Furukawa, M. Takahashi, and M. Mabuchi, "Hydrogen storage properties of nanoporous palladium fabricated by dealloying," The Journal of Physical Chemistry C, vol. 114, no. 2, pp. 868-873, 2010.

[3] X. Wang, W. Wang, Z. Qi, C. Zhao, H. Ji, and Z. Zhang, "Novel Raney-like nanoporous Pd catalyst with superior electrocatalytic activity towards ethanol electro-oxidation," International Journal of Hydrogen Energy, vol. 37, no. 3, pp. 2579-2587, 2012.

[4] C. Zhang, H. Ji, J. Sun, T. Kou, and Z. Zhang, "Fabrication of nanoporous $\mathrm{Pd}$ with superior hydrogen sensing properties by dealloying," Materials Letters, vol. 92, pp. 369-371, 2013.

[5] D. Ding and Z. Chen, "A pyrolytic, carbon-stabilized, nanoporous pd film for wide-range $\mathrm{H} 2$ sensing," Advanced Materials, vol. 19, no. 15, pp. 1996-1999, 2007.

[6] J. Zhang, Q. Bai, and Z. Zhang, "Dealloying-driven nanoporous palladium with superior electrochemical actuation performance," Nanoscale, vol. 8, no. 13, pp. 7287-7295, 2016.

[7] J. Zhang, Y. Wang, C. Si et al., "Electrochemical actuation behaviors of bulk nanoporous palladium in acid and alkaline solutions," Electrochimica Acta, vol. 220, pp. 91-97, 2016.

[8] J. Erlebacher, M. J. Aziz, A. Karma, N. Dimitrov, and K. Sier adzki, "Evolution of nanoporosity in dealloying," Nature, vol. 410, no. 6827, pp. 450-453, 2001.

[9] J. Erlebacher and K. Sieradzki, "Pattern formation during dealloying," Scripta Materialia, vol. 49, no. 10, pp. 991-996, 2003.

[10] M. Hakamada and M. Mabuchi, "Preparation of nanoporous palladium by dealloying: Anodic polarization behaviors of Pd$\mathrm{M}(\mathrm{M}=\mathrm{Fe}, \mathrm{Co}, \mathrm{Ni})$ alloys," Materials Transactions, vol. 50, no. 3, pp. 431-435, 2009.

[11] Z. Zhang, C. Zhang, J. Sun et al., "Ultrafine nanoporous PdFe/ $\mathrm{Fe} 3 \mathrm{O} 4$ catalysts with doubly enhanced activities towards electro-oxidation of methanol and ethanol in alkaline media," Journal of Materials Chemistry A, vol. 1, no. 11, pp. 3620-3628, 2013. 
[12] Y. Ding and J. Erlebacher, "Nanoporous metals with controlled multimodal pore size distribution," Journal of the American Chemical Society, vol. 125, no. 26, pp. 7772-7773, 2003.

[13] Z. Qi and J. Weissmüller, "A hierarchical nested-network nanostructure by dealloying," ACS Nano, vol. 7, no. 7, pp. 5948-5954, 2013.

[14] M. Du, H.-W. Zhang, Y.-X. Li, Y. Liu, X. Chen, and Y. He, "Synthesis of a bimodal porous $\mathrm{Cu}$ with nanopores on the inner surface of Gasar pores: Influences of preparation conditions," Applied Surface Science, vol. 360, pp. 148-156, 2016.

[15] M. E. Cox and D. C. Dunand, "Bulk gold with hierarchical macro-, micro- and nano-porosity," Materials Science and Engineering: A Structural Materials: Properties, Microstructure and Processing, vol. 528, no. 6, pp. 2401-2406, 2011.

[16] Y. He, Y. Jiang, N. Xu et al., "Fabrication of Ti-Al micro/nanometer-sized porous alloys through the kirkendall effect," Advanced Materials, vol. 19, no. 16, pp. 2102-2106, 2007.

[17] M. Hakamada and M. Mabuchi, "Fabrication of nanoporous palladium by dealloying and its thermal coarsening," Journal of Alloys and Compounds, vol. 479, no. 1-2, pp. 326-329, 2009.

[18] M. Hakamada and M. Mabuchi, "Thermal coarsening of nanoporous gold: melting or recrystallization," Journal of Materials Research, vol. 24, no. 2, pp. 301-304, 2009.

[19] I. C. Cheng and A. M. Hodge, "High temperature morphology and stability of nanoporous Ag foams," Journal of Porous Materials, vol. 21, no. 4, pp. 467-474, 2014.

[20] H. Y. Gao, Y. H. He, P. Z. Shen et al., "Effects of Al content on porous Fe-Al alloys," The International Journal of Powder Metallurgy, vol. 52, no. 2, pp. 158-163, 2009.

[21] Z. Zhang, Y. Wang, Z. Qi, W. Zhang, J. Qin, and J. Frenzel, "Generalized fabrication of nanoporous metals (Au, Pd, Pt, Ag, and $\mathrm{Cu}$ ) through chemical dealloying," The Journal of Physical Chemistry C, vol. 113, no. 29, pp. 12629-12636, 2009.

[22] J. Biener, G. W. Nyce, A. M. Hodge, M. M. Biener, A. V. Hamza, and S. A. Maier, "Nanoporous plasmonic metamaterials," Advanced Materials, vol. 20, no. 6, pp. 1211-1217, 2008.

[23] X. Wang, W. Wang, Z. Qi, C. Zhao, H. Ji, and Z. Zhang, "Fabrication, microstructure and electrocatalytic property of novel nanoporous palladium composites," Journal of Alloys and Compounds, vol. 508, no. 2, pp. 463-470, 2010.

[24] A. Wittstock, A. Wichmann, J. Biener, and M. Bäumer, "Nanoporous gold: A new gold catalyst with tunable properties," Faraday Discussions, vol. 152, pp. 87-98, 2011.

[25] A. M. Hodge, J. Biener, J. R. Hayes, P. M. Bythrow, C. A. Volkert, and A. V. Hamza, "Scaling equation for yield strength of nanoporous open-cell foams," Acta Materialia, vol. 55, no. 4, pp. 1343-1349, 2007.

[26] M. Cargnello, J. J. Delgado Jaén, J. C. Hernández Garrido et al., "Exceptional activity for methane combustion over modular Pd@CeO2 subunits on functionalized Al2O3," Science, vol. 337, no. 6095, pp. 713-717, 2012.

[27] T. Fujita, T. Tokunaga, L. Zhang et al., "Atomic observation of catalysis-induced nanopore coarsening of nanoporous gold," Nano Letters, vol. 14, no. 3, pp. 1172-1177, 2014.

[28] P. J. Cappillino, K. M. Hattar, B. G. Clark et al., "Synthesis of mesoporous palladium with tunable porosity and demonstration of its thermal stability by in situ heating and environmental transmission electron microscopy," Journal of Materials Chemistry A, vol. 1, no. 3, pp. 602-610, 2013.

[29] Y. Sun, S. A. Burger, and T. J. Balk, "Controlled ligament coarsening in nanoporous gold by annealing in vacuum versus nitrogen," Philosophical Magazine, vol. 94, no. 10, pp. 1001-1011, 2014.

[30] S. Kuwano-Nakatani, T. Fujita, K. Uchisawa et al., "Environment-sensitive thermal coarsening of nanoporous gold," Materials Transactions, vol. 56, no. 4, pp. 468-472, 2015.

[31] A. Y. Chen, S. S. Shi, F. Liu et al., "Effect of annealing atmosphere on the thermal coarsening of nanoporous gold films," Applied Surface Science, vol. 355, pp. 133-138, 2015.

[32] S. Parida, D. Kramer, C. A. Volkert, H. Rösner, J. Erlebacher, and J. Weissmüller, "Volume change during the formation of nanoporous gold by dealloying," Physical Review Letters, vol. 97, no. 3, Article ID 035504, 2006.

[33] D. M. Artymowicz, J. Erlebacher, and R. C. Newman, "Relationship between the parting limit for de-alloying and a particular geometric high-density site percolation threshold," Philosophical Magazine, vol. 89, no. 21, pp. 1663-1693, 2009.

[34] X. Lu, T. J. Balk, R. Spolenak, and E. Arzt, "Dealloying of $\mathrm{Au}-\mathrm{Ag}$ thin films with a composition gradient: Influence on morphology of nanoporous Au," Thin Solid Films, vol. 515, no. 18, pp. 7122-7126, 2007.

[35] A. M. Hodge, R. T. Doucette, M. M. Biener, J. Biener, O. Cervantes, and A. V. Hamza, "Ag effects on the elastic modulus values of nanoporous Au foams," Journal of Materials Research, vol. 24, no. 4, pp. 1600-1606, 2009.

[36] Y.-C. K. Chen-Wiegart, S. Wang, Y. S. Chu et al., "Structural evolution of nanoporous gold during thermal coarsening," Acta Materialia, vol. 60, no. 12, pp. 4972-4981, 2012.

[37] W. Liu, S. Zhang, N. Li, J. Zheng, S. An, and Y. Xing, "Dealloying Behavior of Dual-Phase Al 15 at.\% Cu Alloy in an Acidic Solution," International Journal of Electrochemical Science, vol. 7, pp. 2240-2253, 2012.

[38] Q. Q. Kong, Y. Liu, L. X. Lian, Y. Tang, X. Wang, and W. Feng, "Characterisation and compressive properties of highly porous palladium materials fabricated by spark plasma sintering with silicon as spacer," Powder Metallurgy, vol. 56, no. 1, pp. 61-66, 2013. 


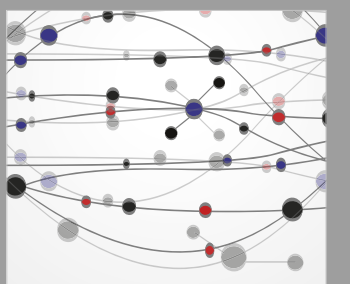

The Scientific World Journal
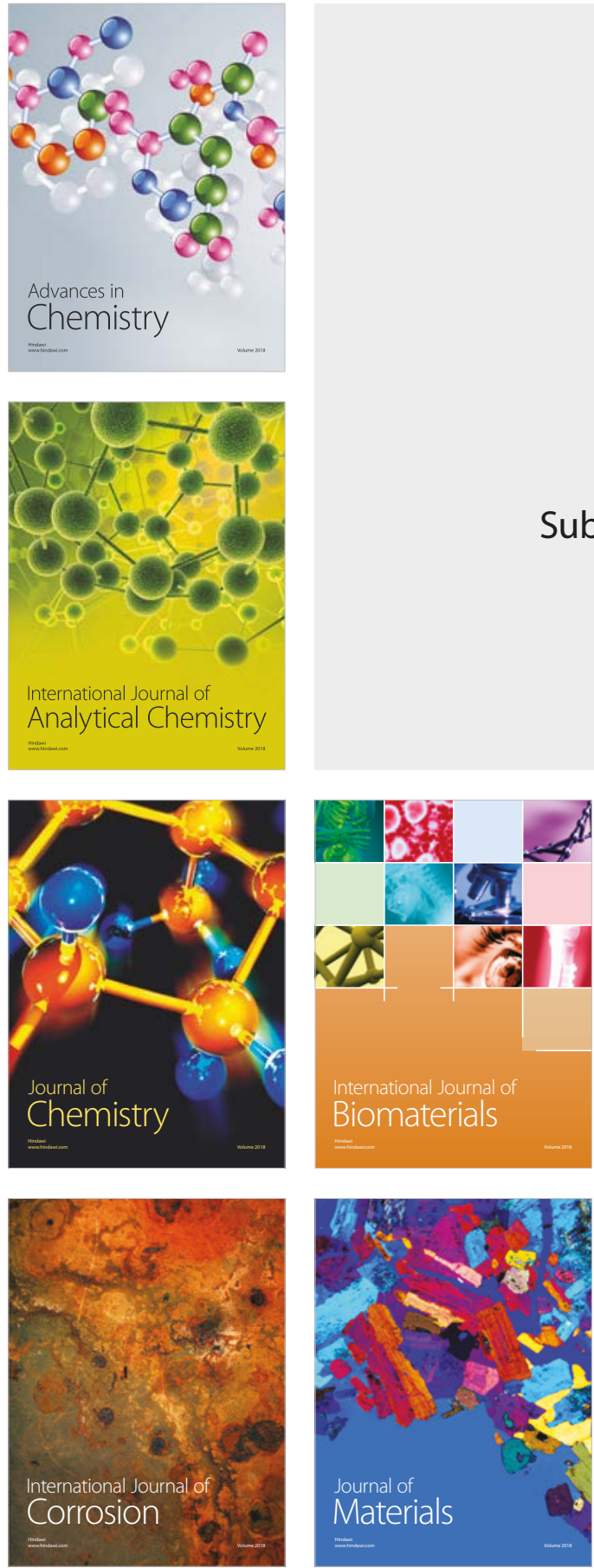

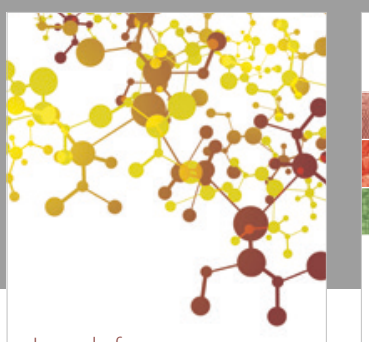

Journal of

Applied Chemistry
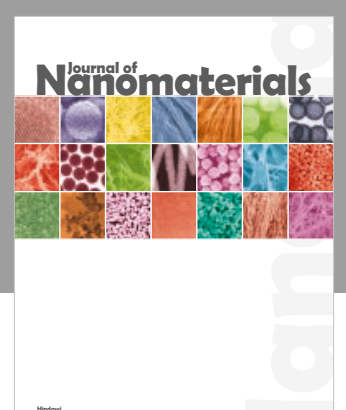

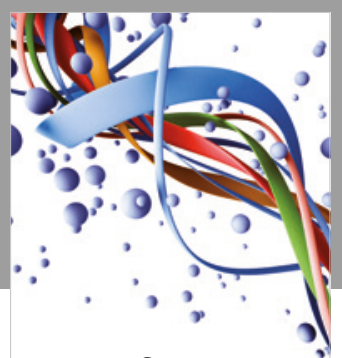

Scientifica

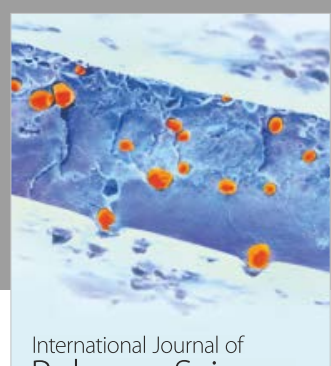

Polymer Science

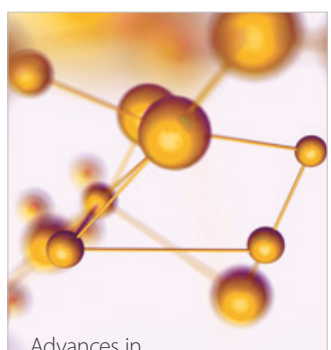

Physical Chemistry
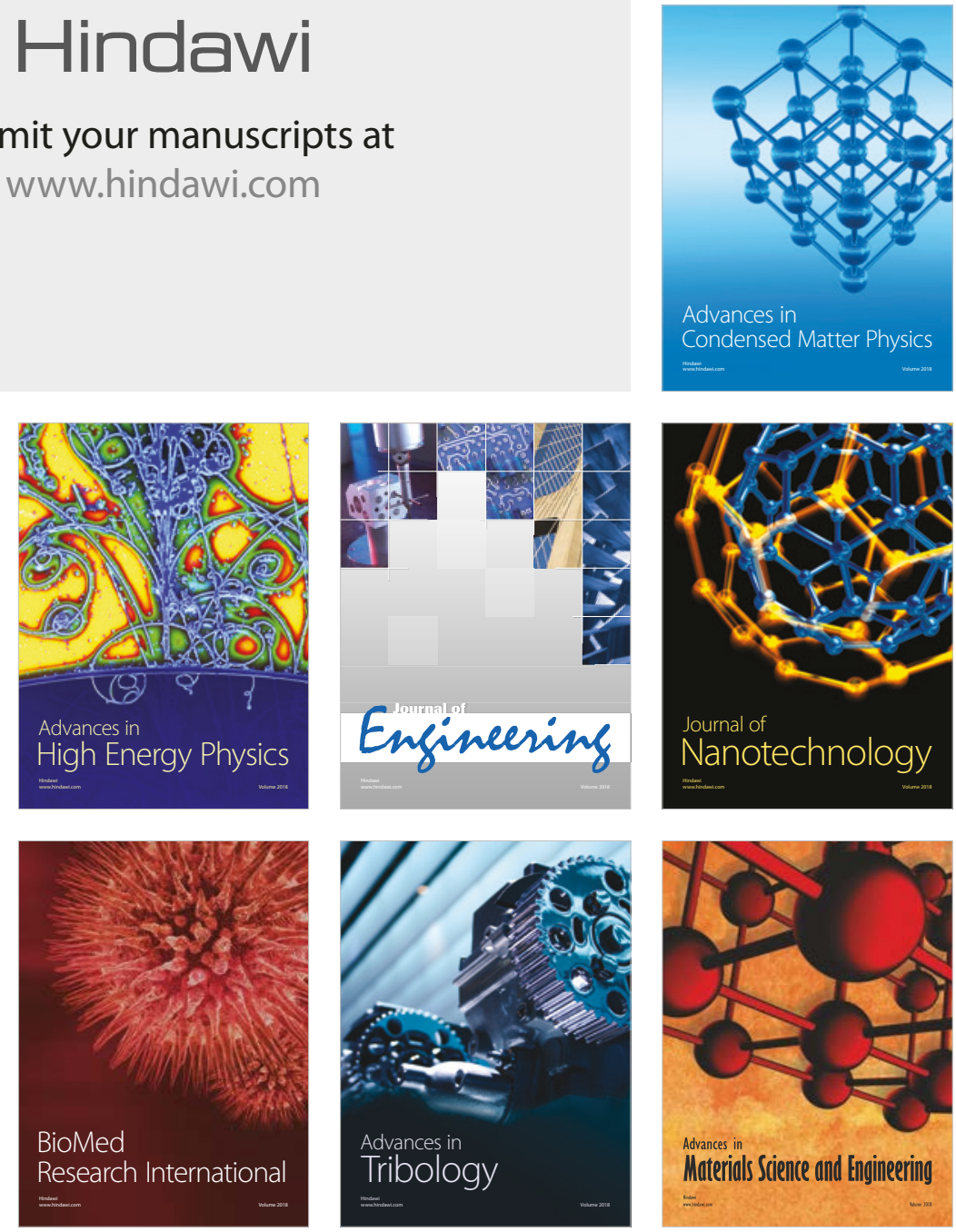